\title{
Regulated Expression of a Calmodulin Isoform Alters Growth and Development in Potato
}

\author{
B. W. Poovaiah ${ }^{2,1}$, D. Takezawa ${ }^{2}$, G. An ${ }^{3,5}$, and T.-J. $\mathrm{HAN}^{2,4}$ \\ 2 Department of Horticulture and \\ ${ }^{3}$ Institute of Biological Chemistry, Washington State University, Pullman, WA, 99164, USA \\ Received September 1, 1995 . Accepted February 1, 1996
}

\begin{abstract}
Summary
A transgene approach was taken to study the consequences of altered expression of a calmodulin isoform on plant growth and development. Eight genomic clones of potato calmodulin (PCM1 to 8) have been isolated and characterized (Takezawa et al., 1995). Among the potato calmodulin isoforms studied, PCM1 differs from the other isoforms because of its unique amino acid substitutions. Transgenic potato plants were produced carrying sense construct of PCM 1 fused to the CaMV $35 \mathrm{~S}$ promoter. Transgenic plants showing a moderate increase in PCM 1 mRNA exhibited strong apical dominance, produced elongated tubers, and were taller than the controls. Interestingly, the plants expressing the highest level of PCM 1 mRNA did not form underground tubers. Instead, these transgenic plants produced aerial tubers when allowed to grow for longer periods. The expression of different calmodulin isoforms (PCM 1, 5, 6, and 8) was studied in transgenic plants. Among the four potato calmodulin isoforms, only the expression of PCM 1 mRNA was altered in transgenic plants, while the expression of other isoforms was not significantly altered. Western analysis revealed increased PCM 1 protein in transgenic plants, indicating that the expression of both mRNA and protein are altered in transgenic plants. These results suggest that increasing the expression of PCM 1 alters growth and development in potato plants.
\end{abstract}

Key words: Solanum tuberosum L., calmodulin, tuberization and transgenic plants.

\section{Introduction}

Calmodulin, a $\mathrm{Ca}^{2+}$-binding regulatory protein is known to play a pivotal role in $\mathrm{Ca}^{2+}$ signaling in eukaryotes. Calmodulin is considered to be multifunctional because of its ability to interact and regulate the activity of a number of other proteins (Cheung, 1980; Roberts et al., 1986; Poovaiah and Reddy, 1987; Poovaiah and Reddy, 1993; Hanson et al., 1994). It is well established that many $\mathrm{Ca}^{2+}$-regulated processes are mediated by calmodulin in both plants and animals (Cheung, 1980; Roberts et al., 1986; Paliyath and Poovaiah, 1984; Veluthambi and Poovaiah, 1984; Rasmussen and Means, 1989; Klee, 1991).

\footnotetext{
1 Corresponding author; fax (509) 335-8690.

4 Present address: Department of Biology, Hallym University, Chunchon, 200-010, Republic of Korea.

5 Present address: Department of Life Science, Pohang University of Science and Technology, Pohang, Kyungbuk, 790-784, Korea.

The presence of multiple calmodulin genes has been reported in animals (Nojima, 1987, 1989; Hardy et al., 1988; Fischer et al., 1988). The existence of calmodulin isoforms has been reported in plants (Poovaiah et al., 1992; Perera and Zielinski, 1992; Gawienowski et al., 1993; Botella and Arteca, 1994; Takezawa et al., 1995). However, the role of these isoforms in plant growth and development is not clearly understood. Altering calmodulin levels is known to affect cell growth and development (Chafouleas et al., 1984; Roberts et al., 1986; Davis and Thorner, 1989; Ohya and Anraku, 1989). Furthermore, decreased calmodulin levels by antisense RNA arrested the cell cycle (Rasmussen and Means, 1989).

Calcium and calmodulin are known to influence tuberization in potato (Balamani et al., 1986; Jena et al., 1989). To study the role of calmodulin isoforms in plant growth and development, several calmodulin genes were cloned and characterized (Takezawa et al., 1995). Among these calmodulin genes (PCM 1-8), the expression of PCM 1 was highest in the 
stem and stolon tip. Studies with transgenic plants carrying the PCM I promoter fused to the GUS reporter gene revealed that promoter activity is highest in the shoot apex and in the tip of the developing tuber, suggesting that PCM 1 may play an important role in shoot growth and tuberization (Takezawa et al., 1995). The role of PCM 1 in growth and development was studied by using transgenic potato plants carrying sense construct of PCM 1 cDNA fused to the CaMV 355 promoter.

\section{Materials and Methods}

\section{Production of transgenic plants carrying sense construct of $P^{P} C M I$}

The expression vector used for this study was the binary vector Ti-plasmid pGA748 which was derived from pGA643 (An et al., 1988) by replacing the small Hind III-Clal fragment with a synthetic oligonucleotide containing multiple cloning sites. The EcoRI site at the left border of pGA643 was destroyed by filling in the sticky ends with dNTPs and DNA polymerase Klenow fragment before addition of the oligonucleotide. The resulting plasmid pGA748 carries seven unique restriction sites (HindIII-Scal-Mlul-Xhol-EcoRI-ClaI$B g /$ II) between the CaMV $35 S$ promoter and the terminator of gene 7. We have previously reported the isolation of a cDNA clone of approximately $1.1 \mathrm{~kb} E c o$ RI fragment carrying the potato calmodulin cDNA clone, PCM-1 (Jena et al., 1989) that contains the entire coding region as well as the $5^{\prime}$ and $3^{\prime}$ untranslated regions. The $636 \mathrm{bp}$ Sial-Hpal fragment containing the calmodulin coding region was used for construction of two plasmids by inserting it into the $S_{c a l}$ site of pGA748. The plasmid pGA924 contains the sense PCM1 ORF. The binary plasmid pGA924 was transferred into $A g$ robacterium tumefaciens LBA4404 by the direct DNA transfer method (An et al., 1988).

Agrobacterium tumefaciens LBA4404 harboring the binary vector was used for transformation of potato (Solanum tuberosum L. var. Russet Burbank; An et al., 1988). The internode sections from in vitro cultured potato seedlings of Russet Burbank were co-cultivated for three days with $A$. tumefaciens as described by Sheerman and Bevan (1988). Kanamycin resistant transformants were selected after four to eight weeks. Transgenic and untransformed control plants were moved to the greenhouse to study their growth and development. Tubers from the transgenic and control plants were harvested, stored, and replanted on three successive occasions over a two year period.

\section{Northern analysis}

Total RNA was isolated as described by Verwoerd et al. (1989) and $5 \mu \mathrm{g}$ of the RNA was denatured with glyoxal/DMSO, electrophoresed in $1 \%$ agarose in $10 \mathrm{mmol} / \mathrm{L}$ sodium phosphate buffer ( $\mathrm{pH}$ 7.0) and transferred to Zeta-probe membrane (BIO-RAD). The $3^{\prime}$ untranslated region of PCM 1 and other isoforms (PCM 5, 6, and 8) were used as templates to prepare riboprobes specific for the sense strand. Hybridization was performed as described by Sambrook et al. (1989). Following hybridization, the filters were washed at $65^{\circ} \mathrm{C}$ in solution containing $0.1 \times$ SSC and $0.1 \%$ SDS.

\section{Western analysis}

Calmodulin isoforms (PCM1 and PCM6) were expressed in $E$. coli using the pET3b expression vector (Studier et al., 1990). These expressed proteins were purified as described by Fromm and Chua (1992). Plant extract $(30 \mu \mathrm{g})$ was separated on the $12.5 \%$ SDSPAGE and transferred onto a PVDF membrane (Millipore). Western analysis was carried out using anti-calmodulin monoclonal antibody as described by Jablonsky et al. (1991).

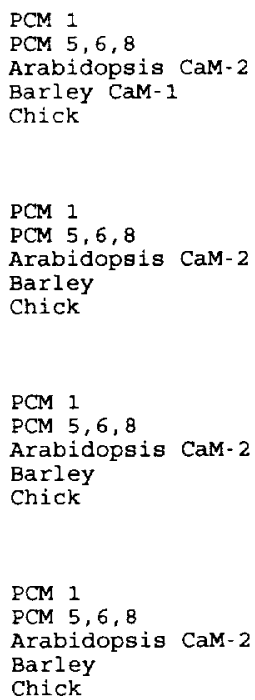

PCM :

PCM $5,6,8$ Arabidopsis CaM-2 Barley CaM-1 Chick

PCM 1

PCM $5,5,8$ Arabidopsis CaM-2 Barley Chick

PCM 1

PCM $5,6,8$

Arabidopsis CaM-2 Barley Chick

PCM 1

PCM $5,6,8$

Arabidopsis CaM-2

Barley

Chick

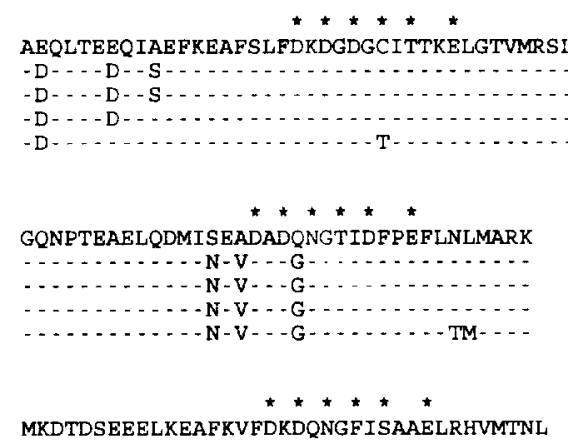

MKDTDSEELLKEAFKVFDKDNGFISAAELRHVMTNL (1) (

$* * * \star *$

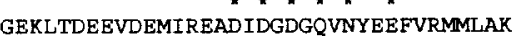
. . . . . . . . . . . . . . - I - - D . . KV - M . . - . - . . . . . K K - - V - - - - I - - D - - KV -M- -

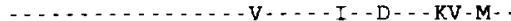

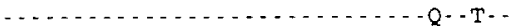
(

Fig. 1: Amino acid sequence comparison of different calmodulin genes (PCM 1, 5, 6 and 8) from potato with Arabidopsis CaM-2 (Ling et al., 1991), barley CaM-1 (Ling and Zielinski, 1989), and chick calmodulin (Putkey et al., 1983). Asterisks indicate the position of amino acids involved in $\mathrm{Ca}^{2+}$-binding. The sequence in the fourth $\mathrm{Ca}^{2+}$-binding region towards the $\mathrm{C}$-terminus are shown (bottom).

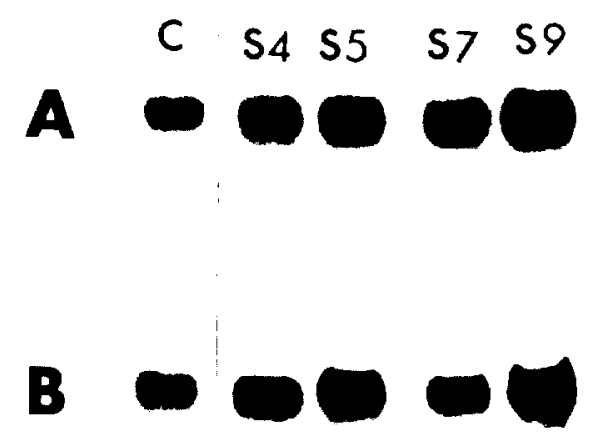

Fig. 2: Northern analysis showing the expression pattern of PCM 1 in stem and leaf tissues of transgenic potato plants (Russet Burbank). (A) leaf tissue (B) stem tissue of transgenic plants carrying sense construct of PCM 1 fused to the CaMV 355 promoter. Control (C); 4 sense plants ( $\$ 4, S 5,57$, and S9). Since the expression in leaf is much lower than in the stem, the autoradiograph for leaf RNA was exposed for longer periods.

\section{Results and Discussion}

\section{Comparison of amino acid sequences of calmodulin isoforms}

Comparison of the deduced amino acid sequences of different potato calmodulin genes (PCM 1, 5, 6 and 8) with Arabidopsis ACaM-2 (Ling et al., 1991), barley (Ling and Zielinski, 1989), and chicken (Putkey et al., 1983) revealed that PCM 1 has several amino acid substitutions, especially in the fourth $\mathrm{Ca}^{2+}$-binding region, suggesting a unique role for this isoform (Fig. 1). In contrast, PCM 5, 6 and 8 are closely related and resemble other known plant calmodulins. 

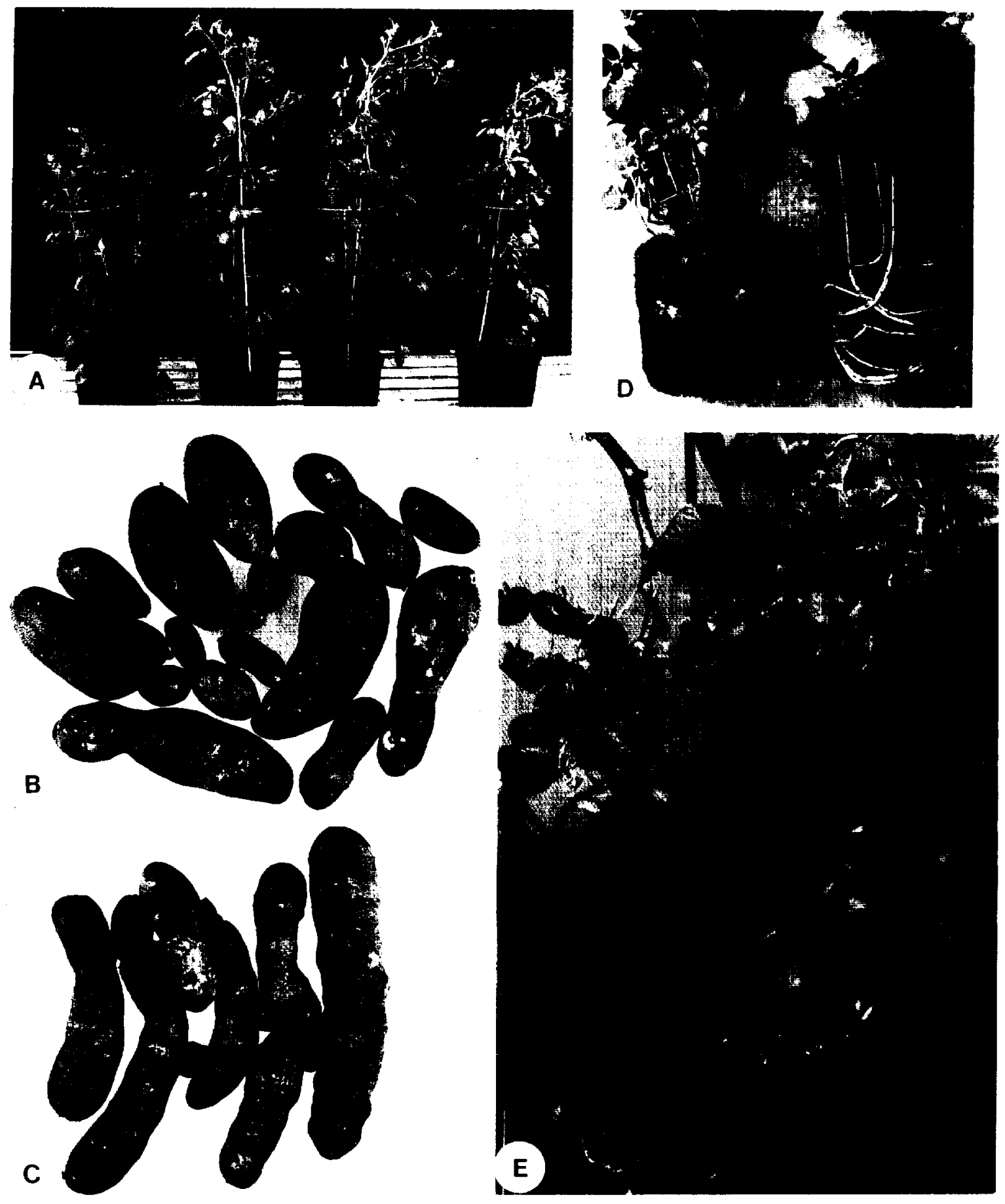

Fig. 3: Comparison of growth and tuberization of transgenic plants carrying sense construct of calmodulin driven by the CaMV $35 \mathrm{~S}$ promoter. (A), Control and 3 transgenic plants carrying sense construct. Plant on the left is the control; to the right are the 3 sense plants (left to right: S4, S5 and S7). Comparison of tuber shape and size with control (B) and S7 transgenic plant (C). Tuberization pattern of S9 transgenic plant expressing the highest amount of PCM1 (D), plant on the left is the control. Photograph showing aerial tubers on the S9 transgenic sense plant $(\mathbf{E})$. 
Altered growth response of transgenic plants carrying the CaMV 355 promoter fused to sense or antisense construct of PCMI

To study the functional role of PCM 1 in growth and development, transgenic potato plants carrying sense construct of PCM 1 cDNA (Jena et al., 1989) driven by the CaMV $35 \mathrm{~S}$ promoter were produced. Northern analysis was carried out using total RNA from leaf and stem of transgenic plants to study altered PCM 1 mRNA. As shown in Figs. 2A and 2B, PCM 1 mRNA was increased in sense plants as compared to controls. These transgenic plants showed differences in internode elongation, apical dominance, height, and branching (Fig. 3). These transgenic plants also varied in their tuberization patterns as compared to the control (Fig. 3). Among several transgenic plants, four transformants carrying the sense construct that showed variations in growth and development were studied in detail.

The sense plants were categorized into three groups based on calmodulin mRNA levels. The first group showed no increase in the calmodulin mRNA (S2, S6 and S8). The second group showed a moderate increase in calmodulin mRNA (S4, S5, S7 in Fig. 2), while the third group showed an increase of mRNA of more than five fold higher as compared to the first group and the untransformed controls (S9, Fig. 2). The first group did not show any phenotypic differences as compared to the untransformed controls. Plants in the second group with a moderate increase in calmodulin mRNA were taller and showed increased stem elongation and strong apical dominance as compared to the controls (Fig. $3 \mathrm{~A}$ ). At the time of harvest, the average height of the control plants was $168 \pm 4.15 \mathrm{~cm}$ and the average height of the sense plants (S4, S5 and S7) was $185 \pm 6.02 \mathrm{~cm}, 203 \pm 6.06 \mathrm{~cm}$, and $203 \pm 4.76 \mathrm{~cm}$, respectively (Fig. $3 \mathrm{~A}$ ). The increased height of the sense plants was primarily due to increased internode elongation. The average internode length of the controls was $3.84 \pm 0.09 \mathrm{~cm}$ and the average internode length of sense plants (S4, S5 and S7) was $4.77 \pm 0.15 \mathrm{~cm}, 5.07 \pm 0.15$, and $5.04 \pm 0.12 \mathrm{~cm}$, respectively. The average number of internodes in control and sense plants was not significantly different.

Transgenic plants in the second group with a moderate increase in calmodulin mRNA (Fig. 2, S4, S5 and S7) formed elongated tubers (Fig. 3C). These results indicate a correlation between PCM 1 expression and tuber development. However, in transgenic sense plants in group 3 with the highest mRNA (Fig. 2, S9) tuber formation was inhibited while stolon elongation was dramatically increased (Fig. 3D). Interestingly, when these plants (S9) were allowed to grow for longer periods, they formed aerial tubers (Fig. $3 \mathrm{E}$ ). Consistent results were obtained when the tubers from these transgenic plants were successively harvested, stored to break dormancy, and replanted on three separate occasions over a two year period.

\section{Expression of calmodulin isoforms in transgenic plants}

Since calmodulin genes are highly conserved, altering the level of PCM 1 mRNA could also influence the levels of other isoforms. Therefore, we have studied the expression of other

\section{3}

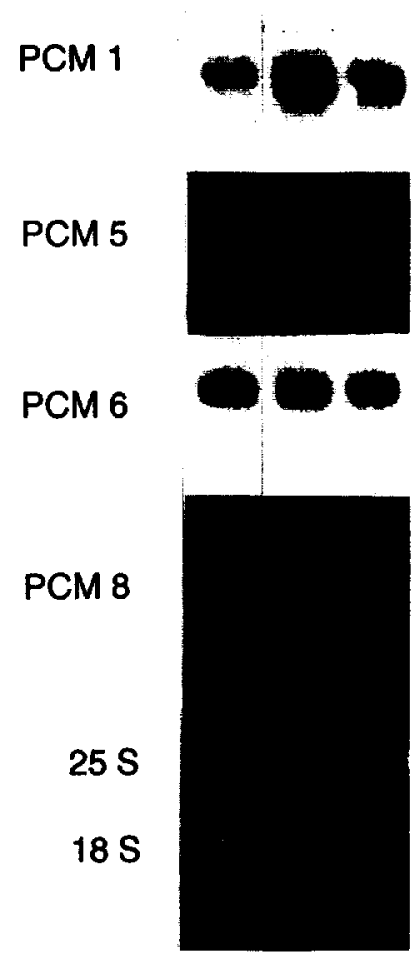

Fig. 4: Northern analysis using gene specific probes showing the expression of different isoforms (PCM 1, 5, 6, and 8) in leaf tissucs. Control (lane 1), S9 transgenic plant (lane 2) and $S 7$ transgenic plant (lane 3). Ethidium bromide-stained gel showing that similar amounts of RNA were loaded in each lane. $25 \mathrm{~S}$ and $18 \mathrm{~S}$ ribosomal RNA bands are shown.

isoforms in transgenic plants ( $\mathrm{S} 7$ and $\mathrm{S} 9$ ) by northern analysis. The expression of PCM 5, 6 and 8 was not significantly altered in these transgenic plants (Fig. 4). These results suggest that the phenotype of sense plants is predominately due to PCM 1.

\section{Changes in calmodulin levels in transgenic plants}

To correlate the phenotypic effects observed in the transgenic plants to the changes in the protein level, western analysis was performed. To distinguish PCM 1 from other calmodulin isoforms, E. coli expressed PCM1 and PCM6 were used as standards. Even though PCM5, 6, and 8 are coded by different genes (Takezawa et al., 1995), their deduced amino acid sequences are identical (Fig. 1). Hence, we have chosen PCM6 as a representative for comparison from this group. PCM 1 and PCM6 can easily be distinguished based on their mobility on SDS-PAGE (Fig. 5). Transgenic plants (e.g., S7, 59) showed a three to five fold increase in protein as compared to control plants.

We have previously generated transgenic tobacco plants carrying the potato calmodulin CDNA (PCM1) in sense and 


\section{1 2 3 4 5

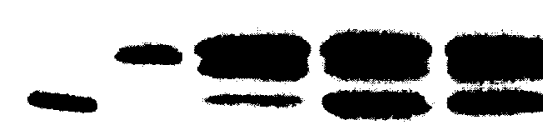 \\ $-20.1$ \\ $-14.4$}

Fig. 5: Western analysis showing the expression of different calmodulin isoforms in control and transgenic plants. E. coli expressed PCM 1 (lane 1), PCM6 (lane 2), untransformed control (lane 3), S9) transgenic plant (lane 4) and $S 7$ transgenic plant (lane 5). Molecular weight standards (kDa) are marked.

antisense orientations driven by the CaMV $35 \mathrm{~S}$ promoter (Poovaiah et al., 1992). These transgenic plants did not reveal significant differences in growth and development. Introduction of barley calmodulin into tobacco did not reveal significant differences in growth and development (Zielinski et al., 1990). Roberts et al. (1992) produced transgenic tobacco plants carrying the methylation mutant (VU-3) calmodulin and normal (VU-1) calmodulin. Transgenic plants expressing the calmodulin methylation mutant (VU-3) showed decreased stem internode, reduced seed and pollen viability, and reduced seed production. However, the transformants expressing (VU-1) were found to be indistinguishable from the control plants. The differences in the transgenic plants carrying VU-3 were attributed to mutant calmodulin. It is evident from these studies that altering the levels of specific isoforms of calmodulin or the post-translational modification of calmodulin can alter growth and development in plants.

\section{Acknowledgments}

This work was supported by the National Science Foundation (Grant No. DCB 9104586), the National Acronautics and Space Administration (Grant No. NAG-10-0061) and the Agricultural Experiment Station (Project No. 0321) to B.W.P. We would like to thank Dr. Hillel Fromm, Weizmann Institute of Science, Israel for providing the monoclonal antibody for calmodulin. We would also like to thank Henry Moore for his help with photography and Craig Whitney for growing the transgenic plants.

\section{References}

AN, G., P. R. Ebert, A. Mitra, and S. B. HA: Pages 1-19. In: Gielvin, S. B. and SChilperport (eds.): Plant Molecular Biology Manual. Martinus Nijhoff, Dordrecht, The Netherlands (1988).

Balamani, K., K. Veluthambi, and B. W. Poovalah: Effect of calcium on ruberization in potato (Solanum tuberosum L.). Plant Physiol. 80, 856-858 (1986).
Botelia, J. R. and R. N. Arteca: Differential expression of two calmodulin genes in response to physical and chemical stimuli. Plant Mol. Biol. 24, 757-766 (1994).

Chafouleas, J. G., L. Lagace, W. E. Bolton, A. E. Boyd, and A. R. Means: Cell 36, 73-81 (1984).

Cheung, W. Y.: Calmodulin plays a pivotal role in cellular regulation. Science 207, 19-27 (1980).

Davis, 'T. N. and J. Thorner: Vertebrate and yeast calmodulin, despice significant divergence, are functionally interchangeable. Proc. Natl. Acad. Sci. 86, 7909-7913 (1989).

Fischer, R., M. Koller, M. Flura, S. Mathews, M.-A. Strehler-Page, J. Krebs, J. T. Penniston, E. Carafoli, and E. E. STREhier: Multiple divergent mRNA code for a single human calmodulin. J. Biol. Chem. 263, 17055-17062 (1988).

Fromm, H. and N.-H. Chua: Cloning of plant cDNAs encoding calmodulin-binding proreins using ${ }^{35}$ S-labeled recombinant calmodulin as a probe. Plant. Mol. Biol. Rep. 10,199-206 (1992).

Gawiknowski, M. C., D. Szymanski, I. Y. Perera, and R. E. ZieIINSKI: Calmodulin isoforms in Arabidopsis encoded by multiple divergent mRNAs. Plant. Mol. Biol. 22, 215-225 (1993).

Hanson, P. I., T. Meyer, L. Stryer, and H. Schulman: Dual role of calmodulin in autophosphorylation of multifunctional CaM kinase may underlie decoding of calcium signals. Neuron 12 , $943-956$ (1994).

Hardy, D. O., P. K. Bender, and R. H. Kretsinger: Two calmodulin genes ase expressed in Arabacia punctulata. J. Mol. Biol. 199, 223-227 (1988).

Jablonsky, P. P., F. Grolig, J. L. Perkin, and R. E. Williamson: Properties of monoclonal antibodies to plant calmodulin. Plant Sci. 76, 175-184 (1991).

Jena, P. K., A. S. N. Reddy, and B. W. Poovaiah: Molecular cloning and sequencing of a cDNA for plant calmodulin: Signalinduced changes in the expression of calmodulin. Proc. Natl. Acad. Sci. USA 86, 3644-3648 (1989).

KLEE, C. B.: Concerted regulation of protein phosphorylation and dephosphorylation by calmodulin. Neurochem. Res. 16, 10591065 (1991).

LiNG, V. and R. E. Zifi.inski: Cloning of cDNA sequences encoding the calciumbinding protein, calmodulin, from barley (Hordeum vulgare L.). Plant Physiol. 90, 714-719 (1989).

Ling, V., I. Perfera, and R. E. Zielinski: Primary structures of Arabidopsis calmodulin isoforms deduced from the sequences of cDNA clones. Plant Physiol. 96, 1196-1202 (1991).

Nojima, H.: Molecular evolution of the calmodulin gene. FEBS Lett. 217, 187-190 (1987).

- Structural organization of multiple rat calmodulin genes. J. Mol. Biol. 208, 269-282 (1989).

OHYA, Y. and Y. ANRakU: Functional expression of chicken calmodulin in yeast. Biochem. Biophys. Res. Commun. 158, 541-547 (1989).

Palimath, G. and B. W. Poovalah: Calmodulin inhibitor in senescing apples and its physiological and pharmacological significance. Proc. Natl. Acad. Sci. 81, 2065-2069 (1984).

Perfera, I. Y. and R. E. Zielinski: Structure and expression of the Arabidopsis CaM-3 calmodulin gene. Plant Mol. Biol. 19, 649664 (1992).

Poovalah, B. W. and A. S. N. Reddy: Calcium messenger system in plants. CRC Crit. Rev. Plant Sci. 6, 47-103 (1987).

- Calcium and signal transduction in plants. CRC Crit. Rev. Plant Sci. 12, 185-211 (1993).

Poovalah, B. W., A. S. N. Reddy, G. AN, Y. J. Chol, and Z. Q. WANG: Calmodulin gene expression and $\mathrm{Ca}^{2+} /$ calmodulin-dependent protein kinase II in plants. Pages 691-702. In: KarsSEN, C. M., L. C. Van Loon, and D. Vreugdenhil (eds.): Progress in Plant Growth Regulation. Kluwer Academic Publishers, Dordrecht, The Netherlands (1992). 
Putkey, J. A., K. F. Ts'us, T. Tanaka, L. Lagace, J. P. Stein, E. C. LAI, and A. R. MEANS: Chicken calmodulin genes: a species comparison of CDNA sequences and isolation of a genomic clone. J. Biol. Chem. 258, 11864-11870 (1983).

Rasmussen, C. D. and A. R. Means: Calmodulin is required for cellcycle progression during $G_{1}$ and mitosis. EMBO J. 8,73-82 (1989).

Roberts, D. M., T. J. Lukas, and D. M. Watterson: Structure, function, and mechanism of action of calmodulin. CRC Crit. Rev. Plant Sci. 4, 311-339 (1986).

Roberts, D. M., L. Besl, S.-H. Oh, R. V. Masterson, J. Schell, and G. Stacey: Expression of a calmodulin methylation mutant affects the growth and development of transgenic tobacco plants. Proc. Natl. Acad. Sci. 89, 8394-8398 (1992).

Sambrook, J., E. F. Fritsch, and T. Maniatis: Molecular Cloning: a Laboratory Manual, Second Edition. Cold Spring Harbor Laboratory Press, Cold Spring Harbor, New York (1989).

Sheerman, $S$. and $M$. W. Bevan: A rapid transformation method for Solanum tuberosum using binary Agrobacterium tumefaciens vectors. Plant Cell Rep. 7, 13-16 (1988).
Studier, F. W., A. H. Rosenberg, J. J. Dunn, and J. W. DubenDORFF: USE OF T7 RNA polymerase to direct expression of cloned genes. Methods Enzymol. 185, 60-89 (1990).

Takezawa, T., Z. H. Liv, G. AN, and B. W. Poovaiah: Calmodulin gene family in potato: developmental and touch-induced expression of the mRNA encoding a novel isoform. Plant Mol. Biol. 27, 693-703 (1995).

Veluthambi, K. and B. W. Poovaiah: Calcium-promoted protein phosphorylation in plants. Science 233, 167-169 (1984).

Verwoerd, T. C., B. M. M. Dekker, and A. Hoekema: A smallscale procedure for the rapid isolation of plant RNAs. Nucleic Acids Res. 17, 2362 (1989).

Zielinski, R. E., V. Ling, and I. Perera: Structure and expression of genes encoding calcium-modulated proteins in higher plants. Pages 141-152. In: Randall, D. D. and D. G. Belvin (eds.): Current Topics in Plant Biochemistry and Physiology. Plant Protein Phosphorylation, Protein Kinases, Calcium and Calmodulin, Vol. 9, University of Missouri, Columbia, MO. (1990). 